Introduction + Health training (2 sessions)

Introduction + Health + Entrepeneurship training ( 6 sessions)

Introduction + Health + Beekeeping training (6 sessions)

Introduction + Health + Beekeeping + Entrepeneurship training (10 sessions)

Intervention started April 2015 and will be completed January 2016. Post intervention data will be collected 3, 6 and 12 months after the last session. As a pilot study, evaluation variables include: availability/cooperation of subjects, research collaborators and institutions, timing, facilities and equipment needed, researcher experience, and costs.

Results Four youth camps were randomly chosen from 243 mapped camps in 4 wards of DSM. Fifteen members of each camp were invited to join. At the introductory session, camps were randomly chosen for intervention arms. Baseline data were collected quantitatively: demographics, health parameters, assets, risk for violence, and reading, writing, math skills. And qualitatively : involvement with community violence, income generation practices, money spending patterns, helpful and deviant deeds, aspirations.

Conclusions This pilot research is providing insight needed to conduct an experimental study to examine sustainable ways to reduce community violence. It builds on government and NGO youth employment initiatives; it is giving insight as to how such initiatives can be most effective.

\section{COMPARING VIOLENT DEATH PATTERNS AND TRENDS IN MEXICO AND COLOMBIA FROM 2000 TO 2012. DIFFERENCES AND SIMILARITIES}

'Jorge Martín Rodríguez Hernández, ${ }^{2}$ Martha Cecilia Hijar, ${ }^{3} J u l i o$ Cesar Campuzano. ${ }^{4}$ Luis Solorzano. ${ }^{1}$ JaverianaUniversity, Colombia; ${ }^{2}$ Mexican National Council for Accident Prevention; ${ }^{3}$ Nacional Institute of Public Health of México; ${ }^{4}$ Entornos Foundation-Mexico

10.1136/injuryprev-2016-042156.344

Background Violent death has been a public health issue in the Americas. In the past few years, this problem has decreased in Colombia, as opposed to the situation in Mexico. This paper aims to analyse and compare violent death patterns and trends in Colombia and in Mexico from 2000 to 2012.

Methods This comparative, longitudinal study used secondary data furnished by the national agencies in charge of recording, processing, and analysing vital statistics in each of the two countries. The causes of violent death recorded in the International Classification of Diseases were analysed. A comparative analysis of cause of death using the variables country, year, age group, cause, sex, and religion was made, obtaining proportions. A multivariate analysis was made using the dependent variable "country", and the independent variables "sex", "age group", and "cause".

Results From 2000 to 2012, there were 472,658 violent deaths in both countries: $59.2 \%$ in Colombia and $40.8 \%$ in México. At the beginning of the period under study, the risk of violent death was six times higher in Colombia than in Mexico; at the end of the period under study, such risk decreased to 1.6 times higher in Colombia than in Mexico. The most affected population is men of working age; the risk of death includes death by firearms and death by sharp weapons.

Conclusions Violent death decreased in Colombia and increased in Mexico during the period under study. However, the risk of violent death is still higher in Colombia than in Mexico. The increase in violent deaths in Mexico is related to the fight against drug trafficking in its different forms, to criminal gangs, and to outlawed groups. In Mexico, the causes of death suggest greater suffering.

\section{THE PUBLIC HEALTH IMPLICATIONS OF SMALL ARMS AND LIGHT WEAPONS (SALWS) INJURIES IN SOKOTO STATE, NORTH WEST, NIGERIA}

${ }^{1}$ Chukwuemeka Okolo, ${ }^{2}$ Ngozi Catherine Okolo. ${ }^{1}$ Society of Nigeria Doctors for the Welfare of Mankind (International Physicians for the Prevention of Nuclear War, Nigeria) Abuja; ${ }^{2}$ Department of Sociology, Faculty of Social Sciences Usmanu Danfodiyo University Sokoto. Sokoto State. Nigeria

\subsection{6/injuryprev-2016-042156.345}

Background A Small Arms and Light Weapons (SALWs) facilitate and prolong violence, which has enormous public health consequences. This study describes the prevalence, types, risk factors of and outcomes of SALW injuries in a relatively insurgent free state. The cases of Small Arms and Light Weapons (SALWs) injuries admitted in Usmanu Danfodiyo University Teaching Hospital, Sokoto (UDUTH) between January 2003- December 2012 were examined. The prevalence of SALW use in Nigeria is unknown, and with the rising spate of ethno-religious conflicts and political unrest, there may be an increase in the propagation of SALWs use and consequent injuries; hence the need to examine the prevalence of hospital admission due to SALW injury and its Public Health implications.

Methods The study was a quantitative research using a cross sectional approach to assess prevalence, risk factors, types of injury and treatment outcomes of small arms and light weapons injuries in UDUTH in Sokoto State of Nigeria using patient folder audit. Data from the case files of 299 randomly selected victims of SALW injuries over a ten-year period was extracted and analysed to determine the prevalence, types of injuries and outcome of treatment. Bivariate analysis of dependent and independent variables were done to establish association with treatment outcome.

Results Analysis of the 299 case files established a prevalence of $0.07 \%$, with $14 \%$ fatality, and peak age range of $26-35$ years. The commonest types of injuries were wounds, systemic organ injuries and fractures. Brain trauma, though not very common had $75 \%$ mortality while systemic organ injury had $24.6 \%$ mortality. Significant association was established between nature of injury, education, residence, area of occurrence, context of injury and year of occurrence and treatment outcome. Nature of injury and residence were the only predictors of treatment outcome.

Conclusions This study established $0.07 \%$ prevalence of SALW injuries with nature of injury and residence as significant predictors of treatment outcome in UDUTH Sokoto. Strategies to promote the prevention of SALW injuries and good treatment outcome should focus on those predictors. 


\section{Consumer Safety}

Parallel Tue 3.5

\section{INJURY AND ACCIDENT DATA COLLECTION EFFORTS IN EUROPE IN SUPPORT OF CONSUMER PRODUCT SAFETY POLICY}

${ }^{1}$ Otmar Geiss, ${ }^{1}$ Stylianos Kephalopoulos, ${ }^{2}$ Tommaso Chiamparino, ${ }^{1}$ Anita Radovnikovic, ${ }^{1}$ Vittorio Reina, ${ }^{1} J o s e f a$ Barrero-Moreno. ${ }^{1}$ European Commission, DG Joint Research Centre, Institute for Health and Consumer Protection, Ispra (VA), Italy; ${ }^{2}$ European Commission, DG JUST, Products and Service Safety Unit, Brussels, Belgium

\subsection{6/injuryprev-2016-042156.346}

Background Availability of data on the external causes of injuries/accidents which includes product related information is a prerequisite to guide targeted preventive actions in the area of consumer product safety and to support market surveillance enforcement and policy efforts in the EU.

Description of the problem Unlike in the USA, no common injury database with meaningful information to support product safety work is currently in force in the EU. Data on injuries/accidents are collected in an extremely patchy and diverse way across Member States. Yet, the amount of data available at national level in diverse fields (e.g. injury datasets, fire statistics, poison centres) can potentially provide relevant information for market surveillance and product safety policy and enforcement purposes. However, it is frequently not comparable due to lack of harmonised methodology and classification, covers only a limited number of injury types or has a limited territorial coverage.

Results/Changes EC (DG JUST and DG JRC) collaborate on injuries/accident data collection for product safety and market surveillance with the aim to: map existing data collection systems on injuries/accidents of relevance for product safety and market surveillance in MS; explore innovative IT tools to improve systems' interoperability; develop a methodology to organise/filter/extract/ use available data trends; identify possible alternatives/solutions with a view to increase the availability of injury/accident data useful for product safety purposes and assessing the related costs.

Conclusions European Commission works towards adding EU value to existing national data collections in MS on accident/injuries in support of product safety and market surveillance with traceable policy impact and societal benefits: informing and boosting the effectiveness of product safety policy actions; improving product safety standards; reducing societal burden of injuries and accidents due to unsafe products and related health costs.

\section{USING MACHINE LEARNING TO CATEGORISE EMERGENCY DEPARTMENT DATA FOR PRODUCT SAFETY SURVEILLANCE}

${ }^{1}$ Kirsten Vallmuur, ${ }^{2}$ Gaurav Nanda, ${ }^{2}$ Mark Lehto. 'Queensland University of Technology, Australia; ${ }^{2}$ Purdue University, USA

\subsection{6/injuryprev-2016-042156.347}

Background Emergency departments (ED) around the world collect valuable injury data with potential to inform consumer product regulators. However, many of these systems store key information in unstructured text fields, making case identification and analysis difficult. Machine learning approaches allow autocoding of large amounts of data, increasing the utility of these data for surveillance. This study aimed to evaluate the performance of different classifiers for categorising mechanisms and objects involved in injury-related ED presentations.

Methods A sample of 100,000 cases from a special injury surveillance system was used to train the classifiers (Naïve Bayesian, support vector machine (SVM) and logistic regression) and algorithms were tested on 10,000 cases. Accuracy results of each classifier were compared. The classifier obtaining the highest accuracy was then applied to state-wide ED text to autocode the data. A sample of cases were manually coded and reviewed to assess the accuracy of the algorithm for the larger dataset.

Results All classifiers were found to achieve high levels of accuracy for categorising mechanism and moderate levels of accuracy for categorising objects involved. The SVM approach showed the highest accuracy, and was used to classify state-wide ED injury data. Over $75 \%$ of the statewide database was assigned a specified mechanism and almost a quarter of cases were categorised as involving a consumer product. Comparison with gold standard manual coding for a sample of cases found high accuracy of the SVM classifier for the statewide data.

Conclusions Consumer product regulators are increasingly requiring an evidence base to support regulatory responses, and ED data provides a valuable yet underutilised source of injury data. Machine learning approaches can be used to quickly and accurately code free text descriptions to categorise data for further extraction, analysis and interpretation.

\section{THE BATTERY CONTROLLED: AN INTER-AGENCY PARTNERSHIP TO ADDRESS A LITTLE-KNOWN RISK TO CHILDREN}

Alessandra Francoia, Ann Weaver. Safekids New Zealand

10.1136/injuryprev-2016-042156.348

Background When a child swallows or inserts a button battery into the nose or ears, it can get stuck in the throat or in the nose or ear canal. Saliva triggers an electrical current causing severe burns and tissue damage within 2 hours. This results in serious injury that may require surgery, or even the death of a child.

Between 2011 and 2013, the National Poisons Centre of New Zealand received 175 calls regarding children under 6 years swallowing or inserting batteries into their nose or ears. 63 children have also been treated at the Starship Children's Health Emergency Department from March 2009 to February 2012.

Children under 6 years old represent the greatest risk. Small children often have easy access to coin-sized batteries and devices that use them, and many parents do not know there is a risk.

Objective Develop an effective collaboration with government and non-government agencies, industry, design experts and medical first responders to proactively address an emerging child injury issue - the ingestion and insertion of powerful coin sized lithium batteries by children.

Results In April 2014, Safekids Aotearoa announced The Battery Controlled - a partnership to raise awareness about this issue and share information with the medical first responders, medical community, regulators, parents, caregivers, manufacturers and retailers.

This effort is committed to helping prevent children from swallowing coin-sized button batteries, and for parents and medical first responders to know what to do if they suspect a child has swallowed a button battery. 